\title{
LUGARES DE CORTEJO ENTRE JÓVENES DE COMAS (LIMA, PERÚ)*
}

Eva Bautista Ruiz
Universidad Católica Sedes Sapientiae
evabr1492@gmail.com

Fecha de recepción: agosto de 2019 Fecha de aceptación: diciembre de 2019

Resumen: Con este trabajo se pretende explorar cuáles son los lugares de cortejo entre un grupo de mujeres y hombres jóvenes pertenecientes a Comas, distrito popular de Lima Norte. El área concreta de estudio corresponde a La Balanza, un barrio pobre situado en los cerros, en la "parte alta”, la de menor nivel socioeconómico y estatus del distrito.

La investigación está basada en un trabajo de campo realizado entre los años 2010 y 2012. Para su desarrollo fueron claves la observación participante y las entrevistas en profundidad efectuadas a 26 jóvenes -13 mujeres y 13 hombres - de entre 18 y 30 años de edad, y a 6 adultos

Este texto se ha elaborado considerando una parte de la tesis Cortejo y amor entre jóvenes del distrito de Comas (Lima, Perú), defendida para obtener el título de doctora por la Universidad Complutense de Madrid (UCM).

** Eva Bautista Ruiz es licenciada en Historia y Antropología de América (UCM), magíster en Estudios Amerindios (UCM) y doctora en Sociología y Antropología (UCM). Fruto de su trabajo de campo en el distrito de Comas, son las investigaciones: "Trabajo femenino y relaciones familiares en una sociedad patriarcal. Estudio de casos en el distrito de Comas (Lima, Perú)" (2009) y la tesis doctoral (2017) arriba mencionada. Ha trabajado como docente en la Universidad Tecnológica de El Salvador (UTEC) (San Salvador) y en la Universidad Católica Sedes Sapientiae (UCSS) (Lima). 
-2 mujeres y 4 hombres - de entre 36 y 51 años. Estos adultos, habituados a relacionarse con jóvenes, se seleccionaron como informantes complementarios, con el fin de contar con más puntos de vista que fortalecieran los datos obtenidos a través de los jóvenes.

El cortejo necesita un proceso previo de selección, un primer encuentro, que suele ocurrir en cualquier espacio de Comas. Se distinguen lugares estratégicos y lugares inesperados para el cortejo. Los amigos ${ }^{1}$ facilitan el proceso del cortejo por medio de presentaciones y proporcionando cierta seguridad en un contexto considerado inseguro. Uno de los cortejos es el meramente sexual, que se asume con normalidad, pero se silencia. Para el cortejo sexual hay lugares específicos como las discotecas, que propician vacilones o encuentros sexuales esporádicos. La práctica del sexo es muy frecuente y se da en casi todos los espacios de Comas, tanto privados (casas, hoteles u hostales, video cabinas, mototaxis) como públicos, teniendo siempre cuidado de no ser vistos. Hay toda una economía para el sexo en la que se diferencian distintos espacios de mayor o menor nivel según el coste. Palabras Clave: cortejo, jóvenes, lugares, sexo, Comas, Lima.

\section{PLACES OF COURTSHIP AMONG YOUNG PEOPLE OF COMAS (LIMA, PERU)}

ABSTRACT: The purpose of this research is to explore what the places of courtship are among a group of young men and women living in Comas, a working-class neighborhood in the northern area of Lima. The specific

1 Quiero aclarar que, con frecuencia, a lo largo del texto, empleo el masculino genérico (como en este caso: "los amigos") en el que incluyo a mujeres y a hombres, con el fin de que la lectura no resulte farragosa. 
study area is called La Balanza, a poor neighborhood located among the "upper area" of the hills, with the lowest socioeconomic status and level.

This research is based in a field work made between the years 2010 and 2012. To carry out this research, observation and detailed interviews to 26 young people ( 13 women and 13 men) among 18 and 30 years old, and to 6 adults ( 2 women and 4 men) among 36 and 51 years old, were really important. Those adults, who are used to interact with young people, were selected as complementary informants in order to get more points of view strengthening the data obtained from the young people.

Courtship needs a previous process of selection, a first meeting that can be anywhere inside Comas. Strategic and unexpected places are differentiated for courtship. Friends may help in the courtship process through introductions and giving certain security among a context considered insecure. One of courtships is the purely sexual one, which is normally assumed but is muted. For sexual courtship, there are specific places like discos that give sporadic sexual encounters. The practice of sex is very frequent and occurs in almost all areas of Comas, both private (houses, hotels or hostels, video-cabins, mototaxis) and public, always being careful not to be seen. There is a whole economy for sex in which different spaces of greater or lower level are distinguished according to the cost. KeYwords: Courtship, young people, places, sex, Comas, Lima. 


\section{Introducción}

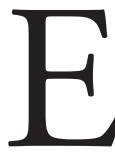

ste artículo ha sido elaborado recopilando información de la tesis doctoral titulada Cortejo y amor entre jóvenes del distrito de Comas (Lima, Perú) (Bautista, 2017). En él se presentan los lugares de cortejo en un grupo de mujeres y hombres pertenecientes a Comas, distrito popular de Lima Norte. El área concreta de estudio corresponde a La Balanza, un barrio pobre situado en los cerros, en la "parte alta", la de menor nivel socioeconómico y estatus del distrito. Se trata de una zona antiguamente estigmatizada y que ahora, gracias a la labor comunitaria del grupo teatral "La Gran Marcha de los Muñecones"2 ha sido potenciada.

Este texto supone una continuación de un artículo previo en el que se aborda cómo es el ritual del cortejo (elementos, fases, duración) entre los jóvenes de Comas, cuántos tipos distinguen los entrevistados o informantes y cuáles han sido sus cambios y evolución respecto a generaciones anteriores ${ }^{3}$. Ahora conoceremos no solo los sitios donde el cortejo se lleva a cabo, sino también los denominados "lugares de selección" previos. Paralelamente, indagaremos otros asuntos como, por ejemplo, qué piensan los jóvenes y adultos comeños de todos estos espacios.

El cortejo es un ritual que frecuentemente pasa desapercibido y que, sin embargo, resulta clave a la hora de entender las relaciones sentimentales o de pareja. Consideramos que este trabajo no supone una continuación de otros similares; el cortejo no ha sido muy estudiado. Existe un creciente interés por el tema del amor y las relaciones de pareja; en los últimos años abunda la literatura acerca de la problemática de pareja y se han presentado

2 La Gran Marcha de los Muñecones es el promotor de la FITECA (Fiesta Internacional de Teatro en Calles Abiertas) que se realiza en Comas cada mes de mayo desde hace dieciocho años

3 Véase Bautista (2018). 
tesis que tratan el amor de pareja entre jóvenes (Vicente, 2015) o adultos (Castrillo, 2015) en España.

\section{Metodología y Marco Etnográfico}

omo ya se ha indicado, el contenido de este artículo se basa en
parte de la tesis doctoral Cortejo y amor entre jóvenes del distrito
de Comas (Lima, Perú) (2017). Dicha tesis se desarrolló a raíz de un intenso trabajo de campo realizado entre los años 2010 y 2012 en el barrio La Balanza de Comas. La incorporación al sitio de investigación fue relativamente sencilla gracias a otro trabajo de campo llevado a cabo de 2006 a 2007 en el mismo lugar.

Para la investigación se seleccionaron 26 jóvenes (13 mujeres y 13 hombres) de entre 18 a 30 años, de distintas ideologías o que se movían en ámbitos diversos como el teatro o las iglesias. Además, se incorporaron desde el inicio seis adultos, con la intención de complementar la información obtenida por parte de los jóvenes. Los adultos fueron tres -2 mujeres y 1 hombre- vinculados al teatro, un diácono (que después se ordenó sacerdote) y dos chamanes. Todos ellos debían reunir requisitos tales como conocer bien el barrio y sus jóvenes, interactuar con ellos cotidianamente o llevar una intensa vida social.

Como técnicas de investigación principales se emplearon: técnicas verbales —entrevistas con informantes clave, historias de vida (32 casos), entrevistas en profundidad-, y observación de conductas (Pelto y Pelto, 1978; Sánchez Fernández, 2019). Los nombres de los informantes (jóvenes $\mathrm{y}$ adultos) son ficticios; cambiados para mantener su privacidad. 
Tabla 1

Informantes Jóvenes

\begin{tabular}{|c|c|c|}
\hline Nombre & Edad & Trabajo \\
\hline Elena & 18 & $\begin{array}{l}\text { limpia junto a su madre (empleada } \\
\text { doméstica) una vez por semana }\end{array}$ \\
\hline Violeta & 19 & $\begin{array}{l}\text { auxiliar de educación en un centro de } \\
\text { estimulación temprana; cosmetóloga }\end{array}$ \\
\hline Rosa & 19 & $\begin{array}{l}\text { no trabaja (se prepara en una academia para } \\
\text { acceder a la universidad) }\end{array}$ \\
\hline Ada & 20 & $\begin{array}{l}\text { no trabaja (estudia una carrera en la } \\
\text { universidad) }\end{array}$ \\
\hline Carla & 21 & $\begin{array}{l}\text { cuidadora en un centro de estimulación } \\
\text { temprana }\end{array}$ \\
\hline Elizabeth & 22 & profesora de danza \\
\hline Alessandra & 22 & regenta una bodega \\
\hline Karina & 23 & $\begin{array}{l}\text { artista en eventos de animación los fines } \\
\text { de semana; profesora eventual de teatro y } \\
\text { danza }\end{array}$ \\
\hline Liliana & 24 & $\begin{array}{l}\text { no trabaja (a la espera de conseguir un } \\
\text { empleo) }\end{array}$ \\
\hline Reina & 25 & $\begin{array}{l}\text { artista en eventos de animación los fines de } \\
\text { semana }\end{array}$ \\
\hline Sara & 26 & $\begin{array}{l}\text { digitadora; artista en eventos de animación } \\
\text { los fines de semana; profesora eventual de } \\
\text { artes plásticas }\end{array}$ \\
\hline Olga & 28 & $\begin{array}{l}\text { ama de casa; vende picarones los sábados en } \\
\text { la puerta de su vivienda }\end{array}$ \\
\hline
\end{tabular}


Adriana

Matteo

Francisco

Edgar

Mario

Daniel

Jesús

Iván

Alberto

Raúl

César

Pedro

Félix

Nicolás
26

28 profesora de Educación Inicial

no trabaja (estudia una carrera en la universidad)

artista (músico) en eventos de animación los fines de semana; cerrajero-soldador; "mil oficios"

no trabaja (estudia una carrera en la universidad)

actor y pedagogo infantil

profesor de danza

en un colegio particular (privado)

empleado en la empresa de máquinas de producción de su tío

no trabaja (está en un programa de formación en panadería)

actor y profesor en diferentes productoras teatrales

fotógrafo

actor en un grupo de teatro; artista en

eventos de animación los fines de semana

músico en eventos de animación los fines de semana

operario de almacén para una empresa

empleado de mantenimiento para aerolínea;

mototaxista 
Tabla 2

Informantes Adultos

\begin{tabular}{ccc}
\hline Nombre & Edad & Trabajo \\
\hline Valentina & 36 & $\begin{array}{c}\text { administradora y actriz de grupo teatral } \\
\text { técnica informática y asistente en eventos de } \\
\text { animación }\end{array}$ \\
Ariadna & 40 & sacerdote \\
León & 39 & chamán \\
Pablo & 46 & director de grupo teatral \\
Rafael & 50 & chamán \\
Hugo & 51 &
\end{tabular}

Se ha tomado como punto de partida el enfoque de género, relacionado con un estudio anterior en el que se abordó la situación de las mujeres trabajadoras comeñas (Bautista, 2009). Es importante fijarse en las posibles desigualdades causadas por el sistema sexo-género y por otros sistemas discriminatorios en base al nivel socioeconómico, nivel de estudios, origen (lugar de nacimiento), ideología (religión, política), estatus, que muchas veces aparecen entrelazados.

Se tuvieron en cuenta "los conocimientos situados" de los que habla Haraway (1988). Se procuró que la investigación no fuese "encubierta", informando anticipadamente de los objetivos y fines de la misma. No hubo muchos problemas a la hora de conseguir informantes, porque el tema parecía ser, por lo general, pertinente.

En relación al contexto o marco etnográfico, este corresponde a Comas, distrito que se ubica en una zona periférica de Lima metropolitana, a unos 15 kilómetros del centro de la capital. Se sitúa en el Cono Norte, 
"Lima Norte" o Lima Conurbana. Sobrepasa el medio millón de habitantes. Es uno de los 43 distritos que conforman la provincia de Lima y uno de los más poblados de Lima y del Perú.

Una de las características que más llaman la atención es su altitud, que va de los 150 a los 811 metros sobre el nivel del mar. Su sorprendente geografía ha servido para dividir el distrito en dos grandes zonas: la zona baja, que es la planicie de Comas; y la zona alta, ubicada en las faldas de los cerros que forman parte de la cordillera andina.

Como distrito, Comas surge tan solo varias décadas atrás, a fines de los 50, tras la llegada de nuevos pobladores (migrantes que quieren asentarse

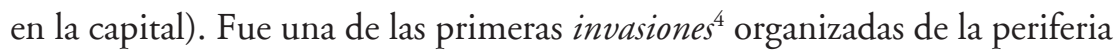
de Lima. En 1958 se produjo la primera llegada masiva de personas a las faldas de los cerros y la aparición de gran cantidad de chozas de esteras. La procedencia de los pobladores de Comas es variada. En el distrito hay gente de la sierra, de la selva, de la costa. Los pobladores provienen principalmente del norte del país (Arellano \& Burgos, 2008).

Comas tiene graves problemas medioambientales y de seguridad. Es uno de los distritos más contaminados de Lima, y percibido por los medios de comunicación como muy inseguro. Otro problema de difícil solución es el de la discriminación. Sus habitantes sufren discriminación y racismo por parte de ciudadanos de otros distritos y de sus propios vecinos (entre ellos "se cholean"; este es un asunto muy complejo). Pero, por supuesto, no todo es negativo. Comas es conocida como la capital cultural de Lima Norte por la cantidad de actividades artísticas y culturales que se realizan en su área.

El nivel educativo medio de los jóvenes comeños es la educación secundaria. Son todavía pocos los universitarios. La mayoría de jóvenes

4 Invasión es un término utilizado en el Perú para el fenómeno migratorio del país; no tiene un matiz peyorativo. 
comienzan a trabajar al culminar la secundaria, si bien cuentan con experiencia laboral desde niños o adolescentes.

El barrio La Balanza de Comas en el que se desarrolló la investigación, se sitúa en el kilómetro 11 del distrito, en la parte alta del cerro, la más pobre.

\section{3. ¿Qué entendemos por “cortejo"?}

\subsection{Definición}

Para contextualizar correctamente nuestro tema, creemos necesario constatar que el fenómeno del cortejo es empleado por los animales para atraer a una pareja con el fin de aparearse y reproducirse. Los estímulos sensoriales de estos animales son señales de tipo visual, olfativo, auditivo y táctil que, al ser percibidos pueden desencadenar comportamientos como cortejo, apareamiento, acercamiento, huida, búsqueda de alimento, defensa de un territorio (Eibl-Eibesfeldt, 1974). Los seres humanos, a diferencia de los animales, no utilizan el cortejo únicamente para la reproducción de la especie, ni tampoco lo hacen en la época de celo; en realidad, no tienen celo.

El cortejo humano puede definirse como la selección y atracción de una persona a otra con el objetivo de tener una relación íntima, la cual implica sexo o sexo y amor. El sexo siempre está presente en el cortejo, como uno de sus objetivos principales. A partir del cortejo, puede ocurrir el establecimiento de la pareja, el compromiso, la cohabitación, el matrimonio y la reproducción. Otra definición más genérica sería la del cortejo como seducción de una persona a otra para enamorarla. 


\subsection{Estudios sobre lugares de cortejo}

En Occidente, el cortejo sucede mediante citas después de un encuentro ocasional. Ahora bien, en algunas sociedades tradicionales, el cortejo es más formal y se rige por reglas muy estrictas. En el siglo pasado, en España, la familia o la comunidad desempeñaba un importante papel ya que fijaba normas que regulaban el cortejo.

Lina Sansano (2003) ha descrito el ceremonial del galanteo, el cortejo y las huidas que emprenden los jóvenes en las Pitiusas (islas de Ibiza y Formentera). Se establecían días y lugares específicos, como los domingos por la mañana a la salida de la ceremonia religiosa, y por la tarde, después de comer -a veces hasta la noche- en el interior de la casa de la muchacha, con autorización previa de su padre. Existían otros días viables para cortejar, dependiendo del criterio de las familias. A veces había más jóvenes cortejadores que, al llegar a la casa, tenían que esperar un turno pactado.

El trabajo "De la ronda al casamiento. Prenoviazgo, Noviazgo y Boda en la Provincia de Albacete" (Diputación de Albacete, 1993) muestra costumbres manchegas de principios del siglo XX, relativas al cortejo.

Ambos estudios destacan cómo las mujeres adoptaban un papel sumiso y pasivo ya que no tomaban la iniciativa. También se constatan transgresiones de las normas para el galanteo, como, por ejemplo, cortejar a escondidas; en esos casos, son los hombres los que más osan hablar de este tema (2003, p. 77).

En España y otros países occidentales la aproximación debe ser paulatina, y se ha de evitar el contacto físico intenso en primera instancia (Maté \& Acarín, 2011, p. 46). Esto no fue así en el pasado de Occidente. En Grecia y Roma antiguas no estaba prohibido el sexo en público, y las parejas podían practicar sexo en la calle. 
En el caso del área investigada en Perú, Rivera (1993) ha relatado cómo era el cortejo hace más de veinte años sobre la base de un trabajo de campo realizado en el barrio La Balanza (Comas). En aquel tiempo, los jóvenes que querían conocerse fuera del círculo familiar, lo hacían en secreto, a escondidas. A veces había cómplices. No se establecían espacios sociales para que las personas se conocieran de un modo más cercano sin tener que asumir obligaciones mutuas. Las formas de evadir el control eran ir a fiestas o estudiar, y, en épocas anteriores, en el trabajo.

Rivera señala el comportamiento considerado correcto en los jóvenes. Las presentaciones de los familiares eran la ocasión adecuada para conocer a un muchacho (1993, p. 72); de lo contrario, los varones tenían que hacer cuidadosas introducciones, pedir disculpas y prometer que sus intenciones eran sanas. Predominaba "la regla del respeto" -que no siempre se cumplía- en el colegio, en la academia y en el trabajo. Una forma permitida de control y de protección, era andar en grupo (1993, p. 74). En el cortejo, los jóvenes, ya presentados, podían conversar, pero no salir juntos; se requería un permiso especial para salir, pero en grupo. Una vez formalizada la relación, cuando se dan los aros (anillos) y los padres (del hombre) han hablado con los familiares de ella y tras un trago (bebida) o cena, se deja que la pareja salga sola a la calle. Hay un gran control social. Rivera destaca que se trata de una sociedad represora que no admite la libertad sexual. No obstante, las relaciones sexuales prematrimoniales son tempranas y frecuentes (1993, p. 69). La familia y el vecindario ejercen una fuerte vigilancia sobre las jóvenes las cuales no pueden permanecer a solas con un varón que no sea su marido (1993, p. 72). Las mujeres perciben que tienen que ser protegidas. Consideran que la calle y los varones significan "peligro", y la casa, el lugar más seguro de permanencia. 
Los estudios sobre cortejo evidencian marcadas diferencias de género. Interesa observar los diferentes roles, preferencias y expectativas de mujeres y hombres; también los cambios y la evolución del cortejo. Así mismo, la antropología ha prestado más atención a aspectos del comportamiento sexual, tales como el acto sexual o la elección de pareja, dejando de lado la seducción y el cortejo. Pensamos que estos últimos son el inicio de la formación de la pareja, y, por tanto, han de ser tomados en cuenta.

\section{Lugares de Selección y Encuentro en Comas}

egún nuestra investigación, estos lugares corresponden a todas las áreas del barrio y sus alrededores dentro del distrito; excepcionalmente, fuera de Comas (por ejemplo, dos informantes, ahora casados, se vieron por vez primera lejos del distrito, en un encuentro vacacional programado por la iglesia evangélica a la que pertenecen); otros jóvenes de origen provinciano o con costumbres muy arraigadas en sus lugares de nacimiento, se conocen en reuniones o fiestas fuera de Comas, donde hay música tradicional o folclórica de sus respectivos pueblos.

Tras estudiar la larga lista de lugares mencionados por los jóvenes, sorprende cómo cualquier espacio es apropiado para el primer encuentro o el cortejo.

Existe una diferenciación "emic"s importante, presente en los discursos de los informantes - y corroborada en la práctica- entre los lugares donde conocer a personas con las que tener una relación estable y los lugares donde se conoce a personas para una relación sexual y esporádica.

$5 \quad$ Elaborada por los propios sujetos entrevistados o informantes. 
Al contrario de lo que ocurre en el resto de espacios, varios informantes consideran que las discotecas, bares o sitios para realizar fiestas solo propician "vacilones" (relaciones sexuales sin compromiso). Esta idea ha sido contrastada con las historias de vida de los jóvenes y se ha observado la ausencia de relaciones de pareja que tengan como origen un encuentro en dichos sitios.

A continuación, se presentan, por orden de frecuencia en los discursos de los entrevistados, los lugares de reunión de los jóvenes que, como se ha dicho, constituyen la mayoría de espacios que conforman el barrio:

- Las discotecas o bares (véase la Figura 1). Son los sitios emblemáticos, aquellos a los que se acude comúnmente con el fin de encontrar pareja. A ellos asisten adolescentes y jóvenes de todas las edades. Sin embargo, dos informantes mujeres hablan de las discotecas como no propicias para conseguir una pareja estable, sino una relación pasajera y efímera.

\begin{abstract}
No sé, lo que pasa es que no pienso que la discoteca sea un lugar para encontrar una pareja. No pienso eso. O sea, definitivamente, no lo he hecho, porque sé que no... o sea, siempre me he dicho: 'eso no, eso no'. No sé. (Reina, 25 años, estudiante de Arquitectura; trabaja como artista)
\end{abstract}

Para Francisco, las discotecas son lugares para un cortejo exclusivamente sexual. Incluso las describe como espacios previos a la iniciación sexual: 
LUGARES DE CORTEJO ENTRE JÓVENES DE COMAS

(LIMA, PERÚ)

Mayormente, de los jóvenes, así como yo, son, que se dedican a ir a discotecas. $Y$ en discotecas, hacerle tomar a chicas, las chicas, que se vayan con ellas... ¿ ¿no? Y pasan las relaciones sexuales. Eso es mayormente lo que abunda acá en Comas. Es lo que siempre pasa.

El informante manifiesta que no es necesario un conocimiento más profundo de la persona para practicar sexo:

Claro, sin conocerse, de un día para otro: 'hola, ¿qué tal?, te invito a tomar'. Se ponen a tomar. 'Vamos, vamos a dormir juntos'. Y se van. (Francisco, 19 años, cerrajero-soldador; trabaja como músico y artista en un grupo de teatro y en eventos de animación).

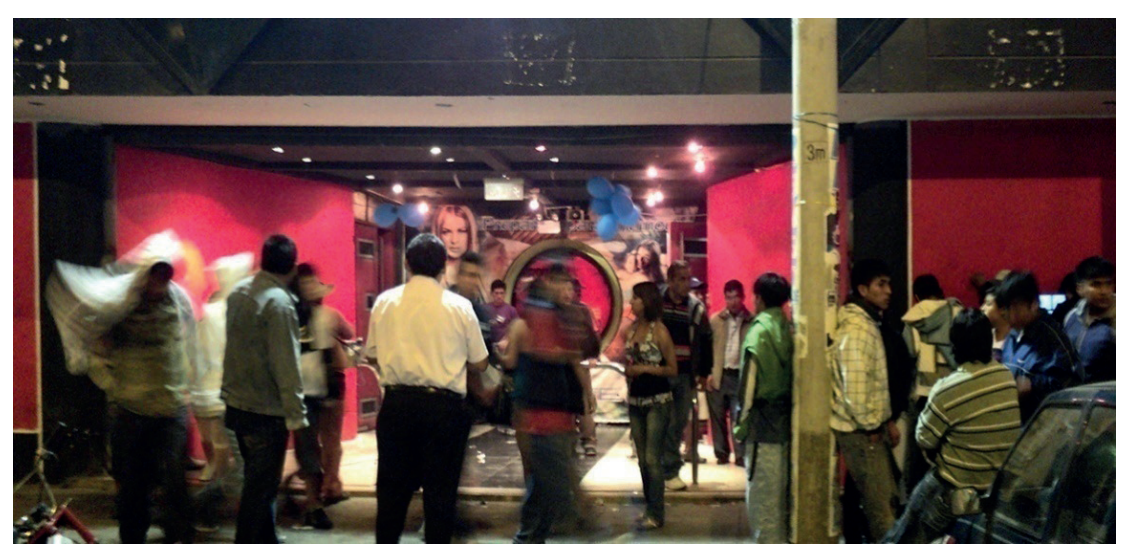

Figura 1. Discoteca en El Retablo (Comas). 
- Los centros de trabajo y estudio como institutos, universidades y academias que preparan a los jóvenes para el ingreso a las universidades. Alberto (23 años, trabaja como profesor y actor en un grupo de teatro comeño y en varias productoras) se encontró por vez primera con la futura madre de su hija en uno de los talleres del grupo de teatro. En un principio no se fijó en ella, que iba como alumna: "era muy niña”. Pero dos años después cambió: "no sé qué pasó (...) Yo la vi mujer”.

- Las iglesias (católicas, evangélicas). Siete jóvenes — una evangélica y seis católicos - reconocen que uno de los motivos por los que concurren a los cultos o actividades eclesiales es la búsqueda de pareja.

Por ejemplo (...) acá en la parroquia, creo que siempre uno va porque... de repente va por diferentes motivos, pero tal vez hay una chica que esté ahí o un chico que te atrae. (Rosa, 19 años, se prepara en una academia para acceder a la universidad)

Este dato es comentado también por dos informantes adultos entrevistados en esta investigación. Uno de ellos, León (39 años, sacerdote), opina que los jóvenes buscan a sus parejas femeninas en la iglesia porque estas reúnen mejores valores sociales y morales:

Dios se vale de muchos medios para unir a las personas también, ¿no? Yo me acuerdo que... hay muchachos que vienen aquí... y se encuentran. Y descubren a las parejas ideales, propias para 
ellos (...) es verdad que hay gente que viene también con ese deseo. Viene con ese deseo de encontrar a la pareja buena o ideal. Todo preparado. Viéndolo así, sí, es una realidad (...) Igual, aquí hoy día, muchos chicos vienen a la iglesia, ¿por qué? Porque ven a algunas chicas de acá de la parroquia, más sanas, más educadas, más formales, y ellos vienen pues, buscando algo diferente.

El otro informante, Pablo (46 años, chamán), destaca a las iglesias como lugares estratégicos para el cortejo:

Más la mayoría, un grupo de muchachos se va a las iglesias. A la iglesia católica, donde hay grupos de jóvenes. Entonces no van a buscar su redención, sino van a buscar chicas. Lo mismo las chicas, ¿ya? Eso es así. Unos en las iglesias, otros en las discotecas, generalmente en grupos de teatro, grupos culturales... por ejemplo, en la iglesia mormona hay jóvenes mayores solteros, jóvenes mayores casados, ¿¿me entiendes? Hay todo eso.

Olga (28 años, ama de casa) y Félix (28 años, operario de almacén en una empresa), unidos en matrimonio, se conocieron gracias a su participación en la Iglesia evangélica. Por su parte, Rosa (19 años, se prepara en una academia para acceder a la universidad) tiene pareja desde hace un año y dos meses. Ambos pertenecen a la Iglesia católica y se conocieron en la parroquia. Los informantes que privilegian el encuentro o la seducción en las iglesias, están pensando más en un cortejo que sirve para formar pareja, destinado a personas que comparten con ellos ciertos valores o creencias. 
- El vecindario. Iván (22 años, en formación profesional como panadero) conoció a una expareja en el colectivo (taxi informal comeño también denominado lanch $a^{6}$ ), en su mismo vecindario. Si se trata de elegir a alguien que vive en el barrio, los parientes más cercanos pueden influir, sugerir a una persona "de buena familia", si bien es el joven (mujer $\mathrm{u}$ hombre) el que finalmente decide, apostando por conocer a la persona que más le agrada. Los jóvenes huyen de la vigilancia y del control familiar, "escondiéndose de los padres, que no siempre los vean" (Edgar, 20 años, estudiante de Ingeniería Química). Las polladas ${ }^{7}$, yunzadas ${ }^{8}$, timberos $^{9}$, fiestas de cumpleaños, son oportunidades en las que los vecinos se reúnen y conocen a más personas. Las pandillas aparecen también en este contexto vecinal como grupos donde se forman parejas.

Son numerosos los jóvenes que se refieren no tanto a "lugares" donde es posible descubrir a otras personas para lograr una relación de pareja, sino

6 Se le denomina así porque cuando sigue la ruta de bajada el chofer suele poner el coche en punto muerto y dejar que continúe su camino por inercia, sin uso del motor.

7 Pollada: peruanismo que significa "típica fiesta o tradicional reunión de carácter popular de la sociedad peruana donde se come principalmente pollo y es realizada con el fin de recaudar fondos para una finalidad determinada". Parece provenir del término parrillada. Es habitual en los sectores populares y se caracteriza por el consumo de alcohol, especialmente cerveza.

$8 Y u n z a d a$ viene de yunza. Es un término peruano que significa "diversión consistente en derribar un árbol previamente dispuesto y adornado con botellas de licor, dulces, etcétera, mientras se canta y baila". La yunza, denominada cortamonte en la costa y umisha en la selva, es típica en carnavales pero puede realizarse también en cualquier época del año. Consiste en plantar artificialmente un árbol cargado de regalos, en torno al cual se baila hasta tumbarlo con los cortes de un machete o hacha.

9 Timberos son fiestas cubanas. Timbero tiene su origen en el término timba, común entre los músicos populares cubanos, principalmente entre los cultivadores del son. Actualmente se ha popularizado en Lima. 
a "eventos" como fiestas (más adelante aparecerán otros como conferencias o reuniones). Muchos de ellos se producen en el vecindario.

- El ámbito del teatro (presentaciones, talleres, agrupaciones) —según seis informantes, cuatro de los cuales se dedican o participan en el teatro- Una joven (Sara, 26 años, técnica informática; trabaja como digitadora, profesora y artista en eventos de animación) sostiene que, si bien se forman parejas en el entorno artístico, estas no suelen permanecer mucho tiempo unidas "por el mismo ritmo de trabajo que llevan". La FITECA (Festival Internacional de Teatro en Calles Abiertas) tiene fama de ser un evento en el que los jóvenes ligan mucho. Se comenta entre risas que las chicas rompen con sus novios antes de que empiece el festival, para poder estar con otros hombres, y regresan con los primeros cuando termina.

En el teatro. En festivales, presentaciones. Fiestas, no sé, lo que conocemos como varités culturales, fiestas artísticas... en esos lugares (ríe). Son buenos lugares para encontrar algo más que una amistad. (Alberto, 23 años, trabaja como profesor y actor en un grupo de teatro comeño y en varias productoras)

- Las fiestas. Con fiestas, los informantes se refieren a cumpleaños, reuniones, celebraciones de quince años llevadas a cabo entre colegiales $^{10}$, niños o adolescentes, en las que se escucha la música conocida como "perreo". Dos jóvenes (Ada, 20; y Mario, 21) no creen que las fiestas sean espacios adecuados para lograr relaciones

10 Hay que resaltar la importancia de las fiestas de colegiales, como las de promoción; pueden entenderse como ritos de paso. 
"serias", es decir, caracterizadas por el compromiso, la durabilidad y la fidelidad. Las personas que se conocen allí terminan en un vacilón. Se ha visto anteriormente cómo dos mujeres consideran las discotecas como lugares no propicios para conocer a una persona con la que lograr una relación estable. Ahora se encuentra la misma percepción respecto de las fiestas en otro par de jóvenes. Tanto en las primeras como en las segundas pueden darse breves y esporádicos encuentros sexuales, de choque y fuga. Parece que en estos casos las relaciones no cuajarán, no serán estables por dos motivos. Primero, porque en ellos "el sexo es previo al amor" y entre los jóvenes tiene mucho calado la idea de que el amor ha de ser previo al sexo. Y segundo, porque las personas que se encuentran es muy probable que pertenezcan a círculos muy diferentes con pocos aspectos en común que les permitan entenderse y permanecer unidas en el futuro. Podríamos aventurarnos y añadir un tercer motivo: la desconfianza, ya que los jóvenes no tienen referencia de las personas con las que tratan en las discos. Lo cierto es que ningún joven informante de esta investigación ha tenido o tiene pareja estable como resultado de un encuentro en una discoteca. Ada (20 años, estudiante universitaria de Matemáticas) conoció a una de sus exparejas en una fiesta. A otras en conciertos de rock y en una discoteca. Estas últimas han sido vacilones que no ha tomado en serio y que apenas han durado una semana.

- La cancha o losa deportiva, donde los jóvenes juegan al fútbol y se relacionan.

- Las reuniones en el colegio, en el grupo de trabajo, con familiares o amigos. 
- Las redes sociales y de contacto. Dos informantes hablan de Internet, de Facebook y de cabinas cerradas (de Internet). Sin embargo, en las cabinas no se da el proceso de "selección" de pareja; dentro de ellas se producen encuentros sexuales de parejas que previamente se han conocido. No es infrecuente que los informantes identifiquen los lugares de selección y de cortejo con los lugares para mantener relaciones sexuales, pues en muchas ocasiones son los mismos (por ejemplo, el parque, la cancha deportiva). Cuando no lo son, como en el caso de las cabinas, creemos que la identificación se debe a la brevedad del "nuevo cortejo" que está ganando peso (el tiempo que transcurre desde que la pareja se conoce hasta que acude a la cabina, puede ser muy corto).

Iván (22 años, en formación profesional como panadero) conoció a su actual pareja haciendo uso de la tecnología. En la televisión vio un anuncio de contacto telefónico gay, se animó a enviar la descripción que le pedían y logró dar con la persona que le llamaba la atención. Pero el caso de Iván no parece ser el más común. Lo frecuente es que se conozca a la persona en una área determinada del barrio antes de relacionarse con ella a través de las redes. En los locales o locutorios de Internet, espacios donde se emplean las "nuevas tecnologías" ocurren muchas veces los primeros encuentros. Elizabeth (22 años, profesora de danza) conoció a su actual pareja cerca del sitio donde trabaja, en el local de Internet: "iba constantemente al Internet”. Solo después de conversar y de que ella le pidiera que la agregara al Messenger, ambos hicieron uso de las redes. Los jóvenes no prevén conocer a alguien de su interés (sexual o amoroso) en estos locales (prueba de ello es que no van preparados ni arreglados como a las 
discotecas); no consideran que sean especialmente propicios para el cortejo. $\mathrm{Y}$, sin embargo, estos lugares "inesperados", se convierten en escenario de encuentros o "flechazos". Una vez que esto sucede, entonces sí que pasan a ser "lugares estratégicos", donde ellos acuden constantemente para ver a la persona interesada. También Sara (26 años, técnica informática; trabaja como digitadora, profesora y artista en eventos de animación) se encontró por vez primera con su actual enamorado en un local de Internet: "No tenía Internet en casa, me lo habían quitado". Y a partir de ahí, al igual que Elizabeth, continuó yendo:

Entonces, cuando yo lo veía a él... yo me iba a Internet, él siempre paraba de negro, cabello crespo, largo; tocaba rock; metal pesado... ¡Sigue igual! (...) Y me llamaba mucho la atención su forma de ser: callado, introvertido, todo lo contrario a mí, que era una loca, ¿no? yo, si veo a alguien triste, estoy por ahí, le hago el habla, nunca puedo venirme tranquila, ni en el carro (ríe)... Pero cuando lo veía a él entonces yo sentía que algo me pasaba, porque si soy tan espontánea con los demás, cuando me veía él, y él me decía: ‘quieres media hora más?', yo: 'Sî́. O sea, siempre mis palabras eran muy cortas. Y hasta el día de hoy me dice: 'oye, tú eras (...)'. Y a él lo veía así, o sea, lo vi y pensé que... ¡inunca lo había visto! Pensé que no era de acá. Por su forma de ser, por lo cuidado que era... Y me llamó mucho la atención. Demasiado la atención.

- Los colegios (según dos jóvenes). Si bien se trata de espacios de niños y adolescentes principalmente, se puede producir en ellos un encuentro de jóvenes, como organizadores de las fiestas colegiales. Pedro (26 años, técnico superior en Informática; trabaja como 
músico en eventos de animación) conoció a su última pareja — con la que estuvo durante un año- yendo a tocar a un colegio que celebraba su aniversario:

Yo estaba en un grupo y la otra chica en un grupo y... decidí romper mi miedo de agarrar, conocer a alguien y me acerqué y le pregunté su nombre y si podía encontrarme con ella algún día. $Y$ así fue que la conocí.

Otros lugares o eventos mencionados por los jóvenes son las actividades sociales en zonas públicas, las conferencias, las casas de amigos, los sitios concurridos, el bulevar de Comas — situado junto a la Municipalidad y la plaza central—, las esquinas e incluso el cementerio. Este último resulta —al igual que las cabinas cerradas de Internet - un lugar de cortejo y de relaciones sexuales más que un espacio para conocer personas. Así es para Alessandra (22 años, administradora industrial, regenta una bodega), cuya casa se ubica justo al lado:

El cementerio también es otro lugar que van entre amigos, toman, están bebiendo y después empiezan a tener relaciones. Y como es de noche... prácticamente lo hacen todo de noche. Los vecinos no pueden salir... solamente escuchamos. Y solamente los que estamos cerca.

Elizabeth conoció a su expareja —el padre de su hija — en casa de una amiga que frecuentaba. A otra joven, Ada (20 años, estudiante 
universitaria de Matemáticas), le sucedió lo mismo, pero no fue en casa de una amiga, sino de una tía que ofrecía pensión a un muchacho.

Para Rosa (19 años, se prepara en una academia para acceder a la universidad) y Karina (23 años, trabaja como profesora de teatro y danza y como artista en eventos de animación), no hay un espacio concreto. Puede ser en cualquier sitio (por ejemplo, caminando).

En ocasiones, los jóvenes no hablan de lugares, sino que se limitan a comentar que conocieron a sus parejas gracias a amigos. Estos últimos aparecen como mediadores para ellos, facilitándoles, en reuniones o en otras circunstancias, por medio de presentaciones, conocer a una persona que les pueda gustar o les guste. En un contexto caracterizado por la peligrosidad, gran parte de la incertidumbre de los jóvenes se ve resuelta por las amistades. Hemos visto cómo Sara se fijó en su actual enamorado en un local de Internet; sin embargo, no lo conoció hasta lograr que un amigo de ambos los presentara (y parece que algo semejante le sucedió a él):

Me enteré de que era amigo de un buen amigo mío. Y yo le dije: ipreséntamelo! Y él me dijo: 'oye, hace cinco minutos, me acaba de decirme él lo mismo.' Hasta que en una reunión... ¡Ya nos habían presentado como tres, cuatro veces y nunca hablábamos nada, los dos...! Hasta que en una reunión ya ahí empezamos, como se dice, ¿no? Ya nos gustábamos como más de medio año. Yo había estado un año sola. Más de medio año que nos mirábamos, nos mirábamos, y nunca nos hablábamos. 
Si se da la circunstancia de encontrar pareja en una discoteca - lo que, como se ha señalado, es excepcional—, ha de darse la mediación de los amigos, como observamos en el caso de otro joven:

En mi barrio, en mis cuadras, mis amigas de mi calle, alguna así que otra de la ciudad lejos, ¿¿no? Por amigas que me decían: 'oye, vamos a discotecas'. Iba a la discoteca, me presentaba a las amigas, las amigas me llamaban, o si no, yo llamaba, para encontrarnos ya, y ahí ya le decía, ¿no? O si no, ella me decía. Listo. (Francisco, 19 años, cerrajero-soldador; trabaja como músico y artista en un grupo de teatro y en eventos de animación)

\section{Lugares de Encuentros Sexuales en Comas}

ecordemos que uno de los fines del cortejo es la relación sexual. El
sexo siempre está presente en el cortejo, como uno de sus objetivos
principales. Si no existe, hablamos de otro tipo de relación, pero no de pareja.

El cortejo puede finalizar o continuar una vez que se ha dado el sexo (al igual que puede hacerlo cuando se ha formado la pareja). En ambos casos, el sexo es siempre clave. ¿En qué lugares tienen los jóvenes comeños sus encuentros sexuales? Nos hallamos en una sociedad muy sexual. Cualquier observador puede percatarse de eso fácilmente, dado que, en Comas, como en toda Lima, abundan los hoteles y hostales destinados al sexo. El paisaje semiurbano, con la presencia de estos sitios asumida con la mayor naturalidad, deja ver con claridad cómo la práctica del sexo es un asunto importante, público (aunque es tabú o silenciado). 
Los jóvenes tienen relaciones sexuales en casi todos los espacios del barrio, al igual que sucede con los lugares de selección y encuentro en el cortejo. Muchos de los sitios referidos, vuelven a repetirse, si bien hemos de destacar que ahora no tienen la misma preferencia. Por ejemplo, para el sexo predominan los hoteles o las casas (viviendas particulares) y se evitan — no se mencionan - los colegios o iglesias.

Los hoteles y hostales de Comas, al igual que los de otros distritos populares, son muchas veces llamativos por los colores y letras con los que se anuncian. Los hay de diversos precios, dependiendo del servicio que brindan (jacuzzi, agua caliente, cable). En general, su coste oscila alrededor de los 10-20 soles (el equivalente a 3-5 euros, aproximadamente). Una abrumadora mayoría de informantes (22) los señala como los sitios elegidos por los jóvenes para tener relaciones sexuales.

Bueno, en los hostales también. La mayoría. Son más las personas que... bueno, yo he ido, también, con mi pareja (...) los hostales. Elizabeth (22 años, profesora de danza)

Nunca he ido... bueno, después sí he entrado... y me muero de vergüenza, y creo que hasta ahora nunca voy a perder la vergüenza. Es que hay cosas que me dan vergüenza, pues (ríe). Parece que no, pero sí. O sea, todo el mundo me ve: 'uy, no tiene vergüenza de nada.' Pero sí, pero mentira, yo soy un manojo de roche, solo que no me dejo ver. (Reina, 25 años, estudiante de Arquitectura; trabaja como artista)

En hostales, a veces en fiestas, más que todo los muchachos que son más libertinos, ¿no? en fiestas... o sea, se conocen en fiestas 
pero se van a un lugar ya pues, hoteles, lugares adecuados. (Félix, 28 años, operario de almacén en una empresa)

Rafael, informante adulto (50 años, director de grupo teatral), afirma que los lugares de relaciones sexuales para los jóvenes son "los hoteles. Un montón de hoteles, hay hasta por gusto ya. Sobran. Y ahora ahí, son sus espacios de inicio."

Además de los hoteles u hostales, las casas de los jóvenes son otros sitios muy frecuentes para tener sexo, citados por 14 informantes. La elección entre hotel y casa depende de la posibilidad económica de los jóvenes para pagar el primero y de si hay privacidad en la segunda — que puede ser de su propia familia o de algún amigo que le preste-. Aún contanto con una vivienda disponible, los jóvenes pueden preferir lugares privados como los hoteles, donde hay más intimidad (no interrumpida ni escuchada por familiares, vecinos), al estar situados fuera del control social. Llevar a alguien a casa implica presentar parte de la vida íntima de una persona (dónde vive, con quién convive), por lo que si son relaciones sexuales que no se estiman de pareja — aunque luego puedan derivar en ella—, es mejor ir a lugares más neutrales, como los hoteles.

En sus casas cuando no hay nadie, me imagino. O sea, aquí en mi casa, siempre hay gente (ríe). No he experimentado eso. Pero yo con mi enamorado, será porque no vive nadie en su casa, siempre he estado en su casa. Y... en su casa. Con César igual. Con William en su casa, igual, a pesar de que su mamá me odiaba. (Reina, 25 años, estudiante de Arquitectura; trabaja como artista) 
De acá, como la mayoría de sus padres trabajan, en sus casas. Eso únicamente. La gran mayoría de mis amigos, en sus propias casas. (Edgar, 20 años, estudiante de Ingeniería Química)

A continuación, exponemos el resto de espacios sexuales que salen a colación - por orden de frecuencia - en las entrevistas a los jóvenes. Cuando se trata de espacios abiertos (parques, parte baja de las viviendas, cancha deportiva, jardines), las relaciones se dan durante la madrugada o en zonas oscuras, donde no hay luz, para no ser vistos:

- Las mototaxis. A falta de coches, muchos comeños ${ }^{11}$ hacen uso de las mototaxis con las que trabajan para mantener relaciones sexuales. Ada las vincula también con la prostitución.

Hasta en las motos, en las mototaxis, creo, porque ahí paran las chicas. Esos son los lugares más frecuentes. Los mototaxistas paran subiendo... O sea, las chicas suben. Sí porque los chicos, cuando están con sus motos, yo veo que paran subiendo diferentes chicas. Generalmente las chicas que suben, o sea, no por movilizar, sino por hacer horas (...) en la moto. Ahí mismo tienen relaciones. Con el mototaxista. (Ada, 20 años, estudiante universitaria de Matemáticas)

Sí, he visto, o sea... con amigas, en lugares, así de casualidad. En motos. (Elizabeth, 22 años, profesora de danza)

He enseñado talleres abajo y en varias partes de acá de Comas. Dicto talleres. Y creo que más he visto a chicos en motos que ver

11 Hablo en masculino porque no vi ni tuve noticia de alguna mototaxista mujer en Comas (actualmente sí hay). 
entrar a un hostal. Sí. Más he visto a jovencitos entrar a motos. (Sara, 26 años, técnica informática; trabaja como digitadora, profesora y artista en eventos de animación)

Mototaxis (...) Ahora las mototaxis van bien tapaditas. Antes eran como medio descubiertas. Ahora van tapadas por detrás, tapadas por los costados, y tapadas por delante. Mucho más íntimo, entonces. Entonces las mototaxis, con el mototaxista, y la chica, ¿no? que siempre lo acompaña, van y se cuadran (estacionan) en algún lugar solitario. Puede ser, no sé: la cancha, en la noche, cuando no hay nadie, o en la pampa. Se cuadran ahí. O en una avenida solitaria donde nadie pasa. Creo que los mototaxistas tienen en este caso, tienen la ventaja. Ventaja que no tienen otros. Esto es... reemplaza al tipo que llega con su carro y se lleva a la chica por todos lados a pasear con el auto y llegan a un lugar solitario y tienen relaciones en el auto. El mototaxi es la manera comeña de este tipo de galán (ríe). (Alberto, 23 años, trabaja como profesor y actor en un grupo de teatro comeño y en varias productoras)

- Las video cabinas de Internet. Hay locutorios o locales con ordenadores y acceso a Internet, que disponen de pequeños espacios (cabinas) donde se dan relaciones sexuales que, en teoría, parecen estar prohibidas. Los regentes o propietarios de estos negocios "hacen la vista gorda" y permiten que sucedan. Lo económico del precio y su fácil acceso — también van menores de edad — hace que sean concurridas, aunque se supone que no están habilitadas para un fin sexual: 
Me dicen también que hasta en las cabinas de internet. $\mathrm{O}$ sea, esas cabinas cerradas de Internet, como que ahí también. Pasó... un día como yo estaba en un instituto de computación, de informática. Justo me había olvidado bajar una info. Y ya ese Internet es bien conocido en Comas. Se sabe que ahí.... en España (Avenida España); el puente, el puente de España, y hay una pollería, la única pollería primera de España, al costado hay un Internet en el segundo piso. Entras y es recontra feo, tétrico, pero ahí van porque las cabinas de ahí son cerradas. Y me acuerdo que yo conté a alguien mi experiencia que había pasado traumática (ríe). Y me dicen: oye ahí entran a tener relaciones. Y yo... Empecé a hacer rápido, a bajar la información de la computadora, porque tenía que ir a entregar, y era el único Internet que abre desde temprano hasta las doce, una de la mañana. Entonces veníamos de trabajar y bajábamos ahí, el Internet estaba abierto. Y empiezo a ver la cabeza de una chica que ¡subía y bajaba, subía y bajaba! Y qué, estaba teniendo relaciones allá al frente. Pucha yo me fui, yo que soy jodida, me fui golpeando... y me retiré, pues. Y ya, pues, cuento así en el grupo de chicos que yo dirigía, ¿no? me decían siempre, eso ya es conocido, es el telo ${ }^{12}$, me decían. Ah ya, tuve la elección de no ir más, porque ¿quién quiere ver en vivo niños ahí, teniendo ahí relaciones?... Mayormente son estos dos puntos acá, como que el Internet y las motos. (Sara, 26 años, técnica informática; trabaja como digitadora, profesora y artista en eventos de animación)

12 Telo: hotel en jerga peruana (en dicha jerga se suelen invertir las sílabas de las palabras). 
Si no, también, video cabinas. Video cabinas, Internet — que son cabinas privadas que vienen con sus cuartos y todo-. Y ahí también, ¿̨no? (...) Internet, normal... es cincuenta (céntimos) la media hora. Un sol la hora. (Francisco, 19 años, cerrajerosoldador; trabaja como músico y artista en un grupo de teatro y en eventos de animación)

En el Internet, también (ríe). En video cabinas. Sí hay cabinas. Por aquí, por la pista (Avenida de España) (...) es privado. Es todo cerrado. Bueno, yo una vez lo hice allí, con un chico, y bueno, a pesar que era, no tan cerrado, pero lógico, que era un cuarto así chiquito y bueno, este... el chico estaba tan caliente, digamos yo, que... bueno, lo hicimos ahí. Hasta que después ya, de ahí, saliendo, el chico (el empleado o regente del local) como que se incomodó. Pero era en el acto, o sea, era para que nos botara en el acto. Y... después de terminar nosotros esto, le reclamó el chico. A mí no me reclamó nada, le reclamó al chico, entonces al chico le empezó a gritar: que esto, que lo otro. Y ya pues. (Iván, 22 años, en formación profesional como panadero)

- Los parques. Daniel (21 años) comenta que ha visto a chicas menores de edad teniendo relaciones con chicos mayores que ellas; Iván (22 años) explica cómo los encuentros se dan en las madrugadas. La mayoría de informantes adultos entrevistados (Valentina, León, Pablo, Hugo), también menciona los parques como lugares de encuentros sexuales para los jóvenes.

- “Cualquier lugar”, “cualquier lado”, “donde sea”. Para Hugo (51 años, chamán) "el lugar" es "en cualquier parque, en cualquier esquina, adonde mejor encuentre el hueco”. 
- Las video cabinas de videos (de alquiler de películas) (véase Figura 2). No todos los jóvenes pueden permitirse el lujo de acudir a hoteles u hostales. Estas video cabinas, diferentes a las de Internet, son sitios para parejas más económicos, clandestinos y muy frecuentados. En la Avenida Túpac Amaru de Comas hay dos. Se trata de comercios que alquilan cientos de DVD y que tienen en la trastienda, de manera encubierta, pequeños habitáculos o cuartos con sofás donde las parejas pueden ver una película — novedosa, pornográfica, "la que sea"- mientras transcurren sus encuentros sexuales. ${ }^{13}$ El tiempo del servicio depende de lo que dure la película, una hora y cuarenta minutos aproximadamente. Los precios varían según el filme - y la comodidad del recinto-. Lo habitual es que cuesten cinco soles (menos de dos euros).

El primer comercio de la avenida Túpac Amaru que alquila video cabinas cuenta con tres salas. En una de las visitas realizadas a este establecimiento, una mañana cualquiera de un día laborable, las tres están ocupadas. El segundo comercio, que lleva años en funcionamiento, posee nueve video cabinas. Los fines de semana (domingos incluidos) todas están repletas. Este nivel de ocupación muestra lo concurridas que son. Hace algún tiempo había video cabinas — que ya no existen - en la avenida de España. Se transformaron en locutorios de Internet.

13 Un profesor e investigador de la Pontificia Universidad Católica del Perú me comentó (en conversación privada) que en el centro de Lima hay video cabinas similares cuyos usuarios son homosexuales y en las que se da también la prostitución (homosexual). No tengo conocimiento de que esto suceda en Comas, si bien la prostitución es común, existiendo numerosos prostíbulos. 
Si no, también, video cabinas (...) ¿ ¿video cabina? Para ver video, cuesta cinco soles. (Francisco, 19 años, cerrajero-soldador, trabaja como músico y artista en un grupo de teatro y en eventos de animación)

Hay hasta en video cabinas, también. Que entran dos personas, ahí. Te ponen una película pornográfica. (Iván, 22 años, en formación profesional como panadero)

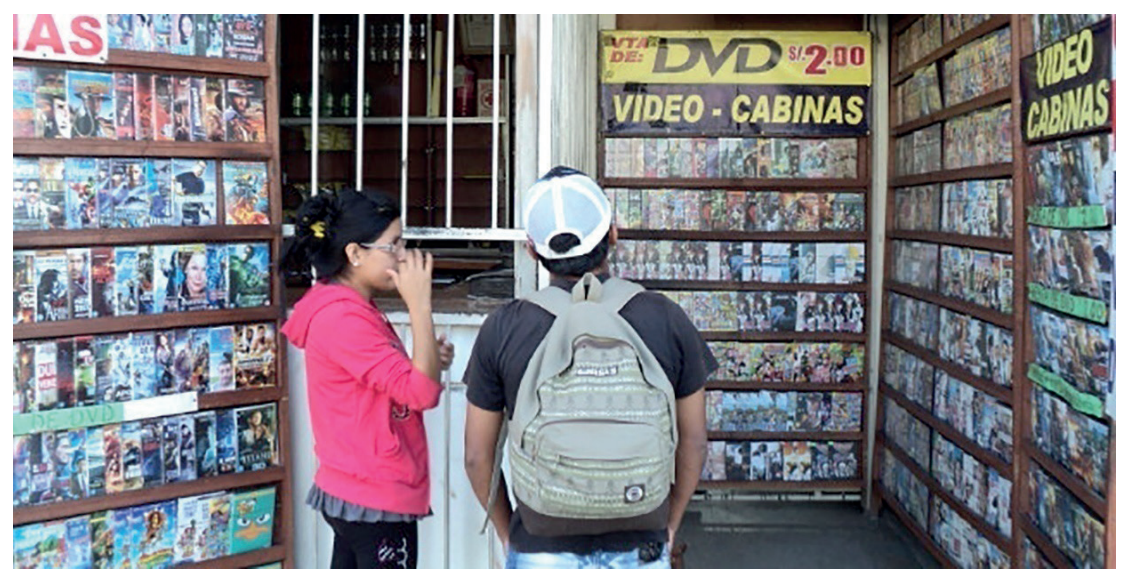

Figura 2. Pareja de jóvenes comeños frente a un local de video cabinas.

- Bajo las casas o a su costado.

- La cancha o losa deportiva (durante la madrugada).

- El jardín — cuando no hay opción de ser vistos-.

- El baño (de cualquier establecimiento o local). 
Por último, hay lugares que los jóvenes mencionan una sola vez, como: cerros, postas (centros de salud), sedes de las Organizaciones de Sobrevivencia, coches de amigos, pasadizos, pasajes, discotecas, lugares oscuros, esquinas, casas abandonadas, cuartos alquilados o el cementerio.

Durante conversaciones informales en La Balanza se me ocurrió preguntar si el cementerio, ubicado a la izquierda del mismo barrio, en el cerro, era un lugar para practicar sexo. La sorpresa fue grande cuando me contaron que dentro de él había un sitio, llamado "Sodoma y Gomorra" porque "allí se liaban primos con primas, todos con todos". Hay que señalar que el cementerio es un espacio peligroso, sobre todo cuando anochece.

Tres informantes adultos sacan a colación estos lugares: Valentina (36 años, administradora y actriz de grupo teatral), destaca "los sitios oscuros, porque acá mi vecino me dice que acá, incluso en los árboles, que está más oscura esa zona, por eso nos sentamos: ‘ ipongan la luz, por el árbol de ahí, porque hay mucha, mucha sombra!'”; León (39 años, sacerdote) 马abla de los cerros y del cementerio; y Pablo (46 años, chamán), de cerros y casas abandonadas.

Algunos informantes se muestran inseguros en sus respuestas. No saben qué contestar, ignoran los lugares donde los jóvenes tienen relaciones sexuales, comentan lo que "han escuchado" o lo que imaginan. Sin embargo, dentro de las opciones que sugieren, se repiten continuamente las casas y los hoteles u hostales. 


\section{Conclusiones}

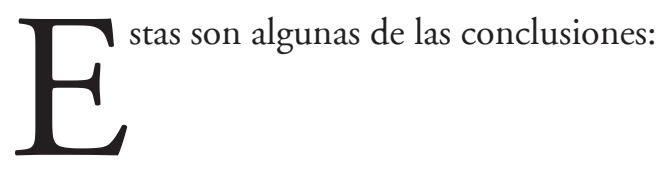

- El cortejo entre los jóvenes de Comas requiere un primer encuentro cara a cara, que normalmente ocurre en el distrito, en cualquier espacio del barrio.

- Hay lugares estratégicos para el cortejo, como las iglesias, donde los jóvenes no acuden de forma exclusiva para el culto, sino porque están interesados en conocer a una pareja que reúna determinadas condiciones atractivas para ellos, como valores y creencias.

- Otros sitios para el cortejo son inesperados, como los locales de Internet, donde los jóvenes no van con la intención de conocer a alguien especial — prueba de ello es que no se arreglan y acicalan especialmente para ello-.

- Los amigos facilitan conocer a la persona deseada, pues actúan como mediadores, proporcionando información y cierta tranquilidad en un contexto percibido como peligroso e inseguro.

- Los jóvenes entrevistados buscan un cortejo más lento para conseguir pareja.

- La familia puede influir a la hora de seleccionar a la pareja deseada, aunque actualmente ha dejado de tener el peso de antaño.

- El cortejo que solo tiene como objetivo la relación sexual, se asume como normal, aunque se silencia, de tal manera que parece que, para tener sexo, no es necesario ritual ni seguir una pauta.

- Hay lugares destinados a este tipo de cortejo, como las discotecas o bares, y situaciones especiales, como las fiestas. Se considera que 
estos espacios y eventos propician vacilones, encuentros sexuales esporádicos, y hacen inviable un cortejo que tenga como fin la búsqueda de pareja estable.

- Para lograr pareja estable primero hay que conocerse mejor, y después tener relaciones sexuales porque pervive la idea de que "antes del sexo tiene que haber amor", y solo se logra saber si hay amor conociendo a la persona. En la práctica, en mi muestra de informantes no hay relaciones de pareja estables que hayan tenido como origen un encuentro en los lugares considerados propios para el vacilón.

- Uno de los fines del cortejo es el sexo. La práctica del sexo es muy frecuente entre los jóvenes y se da en casi todos los espacios de Comas, teniendo siempre cuidado de no ser vistos; es un asunto público pero silenciado.

- Las relaciones sexuales en espacios abiertos como parques o canchas acontecen en especial durante la noche

- Hay una economía para el sexo en la que se distinguen espacios de mayor o menor nivel, según el coste. Las casas particulares y los hoteles u hostales son los lugares habituales y preferidos para las relaciones sexuales. Su elección depende de factores como la economía o la privacidad de la que los jóvenes puedan disponer.

- Existen otros espacios privados más económicos que los hostales como las mototaxis, las video cabinas de Internet y las video cabinas de videos. 


\section{REFERENCIAS}

Arellano, R. \& Burgos, D. (2008). Ciudad de los Reyes, de los Chávez, los Quispe.... Lima, Perú: Arellano Investigación de Marketing.

Bautista, E. (2009). Trabajo femenino y relaciones familiares en una sociedad patriarcal: análisis de casos en el distrito de Comas (Lima-Perú) (Tesina doctoral inédita, Universidad Complutense, Madrid, España).

Bautista, E. (2017). Cortejo y amor entre jóvenes del distrito de Comas (Lima, Perú) (Tesis doctoral inédita, Universidad Complutense de Madrid, Facultad de Ciencias Políticas y Sociología, Madrid, España). Recuperada de http://eprints.ucm.es/47355/1/T39896.pdf

Bautista, E. (2018). El cortejo entre los jóvenes de Comas (Lima, Perú). Studium Veritatis, 16(22), 53-103. Recuperado de https://studium. ucss.edu.pe/index.php/SV/article/view/283/342

Castrillo, M. C. (2015). Amor, género y clase social. La experiencia de los adultos jóvenes en la ciudad de Madrid (Tesis doctoral, Universidad Complutense de Madrid, Facultad de Ciencias Políticas y Sociología, Madrid, España).

Diputación Provincial de Albacete. (1993). De la ronda al casamiento. Prenoviazgo, Noviazgo y Boda en la Provincia de Albacete. Zahora, (57), 143-153. Recuperado de https://issuu.com/revistazahora/ docs/zahora 57

Eibl-Eibesfeldt, I. (1974). Etología. Introducción al estudio comparado del comportamiento. Barcelona, España: Omega. 
Haraway, D. (1988). Situated Knowledges: The Science Question in Feminism and the Privilege of Partial Perspective. Feminist Studies, 3(14), 575-599.

Maté, C. \& Acarín, N. (2011). Encuesta sobre la seducción y el cortejo a los estudiantes de la Universitat Pompeu Fabra (20 a 27 años). Summa Psicológica UST, 8(2), 45-52.

Pelto, P. J. \& Pelto, G. H. (1978). Anthropological research. The structure of inquiry. Cambridge, Reino Unido: Cambridge University Press.

Rivera, C. (1993). María Marimacha: los caminos de la identidad femenina, Pontificia Universidad Católica del Perú.

Sánchez Fernández, J. O. (2019). Antropología. Madrid, España: Alianza Editorial.

Sansano, L. (2003). El ceremonial del galanteo, el cortejo y las huidas. Estrategias matrimoniales en el contexto rural tradicional de las Pitiusas, Narria, 71-80. Recuperado de https://repositorio.uam.es/ bitstream/handle/10486/8652/46222 11.pdf?sequence $=1$

Vicente, A. (2015). Representaciones y prácticas del amor entre la juventud española (Tesis doctoral, Universidad Complutense de Madrid, Facultad de Ciencias Políticas y Sociología, Madrid, España). 